\title{
11. Data visualization and transparency in the news
}

\author{
Helen Kennedy, Wibke Weber, and Martin Engebretsen
}

\begin{abstract}
This chapter explores the role of data visualization in relation to transparency in the news, a field in which a decline in trust and a subsequent need to reassert credibility is an ongoing challenge. Being transparent about how the news is produced is seen as one way of generating trust, yet there has been very little empirical research into transparency practices in newsrooms. Our chapter fills this gap, focusing on transparency and data visualization. We argue that working with data visualization involves particular enactments of transparency, many of which are surprisingly not visual.
\end{abstract}

Keywords: Transparency; Uncertainty; Objectivity; The news; Journalism.

\section{Introduction: Data visualization in the news}

Visual representations of data play a central role in the recent expansion of data-driven news. From simple bar charts and line charts to more sophisticated chart types, data visualizations (or dataviz) are assumed to have the capacity to engage audiences, a view that extends beyond the news. At the same time, the news is experiencing other changes and challenges. At the time of writing, the global political climate is characterized by claims that we are living in a 'post-truth' world, in which people have had enough of objective facts and data. In this context, transparency, seen for some time as a trust-generating mechanism appropriate to the networked age, is believed to make it possible for audiences to see how the news is produced and therefore to establish trust (Singer, 2010).

However, there has been very little empirical research exploring how transparency gets done in newsrooms (Coddington, 2015 is one exception)

Engebretsen, M. and H. Kennedy (eds.), Data Visualization in Society. Amsterdam: Amsterdam University Press, 2020 DOI 10.5117/9789463722902_CH11 
and none that focuses specifically on data visualization. This is surprising, because scholarship on data visualization frequently addresses similar debates and concerns to those outlined above. For example, commentators note that data visualizations are associated with characteristics such as truthfulness and objectivity (e.g. Masson \& van Es, 2017), and this can make them seem trustworthy.

In this paper, we address the empirical gap in the literature by exploring the role of data visualization in relation to transparency and trust in the news. Drawing on empirical research into the uses, roles, and forms of data visualizations in newsrooms in six European countries, we argue that for respondents in our research, working with data visualization involved particular enactments of transparency, many of which are surprisingly not visual. We suggest that dataviz transparency is an increasingly important journalistic norm, understood as a 'moral prescription for social behavior' (Schudson, 2001, p. 151), but that how to 'do' transparency remains in a state of 'interpretative flexibility', undetermined and still under negotiation (Wyatt, 1998). We proceed to situate our research in the context of relevant debates, after which we present our methods and findings.

\section{Transparency in the news}

Transparency, or revealing 'as much as possible about sources and methods' (Kovach \& Rosenstiel, 2007, p. 92), is increasingly important in the news. This can be seen in the fact that, in 2014, the Society of Professional Journalists revised its ethical code to include transparency as a key ethical principle (Vos \& Craft, 2017). Karlsson (2010) argues that transparency represents a form of openness in news practices, which makes it possible for audiences to see how the news is produced, and so makes news producers more accountable to their audiences. Kovach and Rosenstiel (2007) understand transparency as journalists being honest about what they know and how they came to know it. Similarly, Allen (2008, p. 328) defines it as 'making public the traditionally private factors that influence the creation of news'.

While some writers believe that transparency affects how audiences trust the news, others disagree. Karlsson, Clerwall, and Nord (2017) propose that efforts to promote transparency may be limited in their ability to restore trust. Others are cautious about its implementation: Karlsson (2010) argues that transparency can become routinized and separated from its normative intent, and Singer (2010) argues that some journalists see the requirement for transparency as an intrusion to their automony. 
A number of commentators pit transparency against the enduring and contested journalistic norm of objectivity. Some argue that transparency enables a superior form of truth-telling to objectivity. Weinberger (2009) proposes that whereas objectivity was suited to a paper age, transparency is a more appropriate trust-generating mechanism in a networked age, in which links direct readers to the sources that have been consulted and the choices that journalists have made, persuading readers to accept ideas as credible the way that objectivity used to. Belief in the need for transparency predates the current, so-called crisis of trust in the news, but the need becomes more pressing in this context.

Conceiving of transparency and objectivity as distinct is not inevitable, as the same practices which are seen by some commentators to enhance transparency are seen by others as relating to the objectivity norm. McNair (2017) notes that objectivity has historically been achieved through mechanisms such as using credible sources and corroboration of information, precisely the things that transparency practices aim to reveal and enable. McNair claims that practices like making storytelling choices explicit and providing audiences with tools to look behind the scenes and interact with news stories represent journalists' engagement with the objectivity norm, albeit in the form of an acknowledgement of its limitations.

While many writers evoke the objectivity norm when discussing transparency, Anderson (2018), also concerned with re-establishing trust in the news, focuses on uncertainty. He proposes that for journalism to be trusted and to be seen to be pursuing honesty and sincerity, it needs to be more embracing of its uncertainties. Tracing its recent history, Anderson argues that journalism has come to professional maturity by honing its drive for factual certainty. As a result, it ends up proclaiming to be 'more scientific than science itself' (p. 181), given that science more readily acknowledges the uncertainties in which it deals. News journalism's increasing confidence in its ability to 'convey reality with a type of a scientific certainty' (p. 178) has led to the distrust in journalistic truth claims that we are currently witnessing, in Anderson's view.

McNair's call for 'the reassertion of objectivity as an aspirational quality standard' (2017, p. 1328) and Anderson's proposal that news journalism needs to acknowledge its uncertainties are both motivated by a concern to re-establish trust, and both point towards the need for greater transparency. What McNair sees as objectivity work and Anderson sees as uncertainty work both require transparency practices. As the use of data visualization in the news proliferates, it is important to investigate empirically whether news 
professionals see working with dataviz as enabling them to 'do transparency', navigate uncertainties, and re-establish trust, especially given related debates in data visualization research.

\section{Transparency in data visualization and its relationship with objectivity and uncertainty}

Debate about data visualization focuses on similar issues to debate about transparency in the news, especially in its relationship to objectivity. Kennedy, Hill, Aiello, and Allen (2016) argue that data visualizations are imbued with 'the quality of objectivity', which is in turn associated with characteristics such as trustworthiness. Data visualizations' appearance of objectivity has a number of origins: they report numbers, historically trusted because they appear universal, impersonal, and neutral (Porter 1995); and they are associated with science, meaning they are sometimes seen to be objective and trustworthy (Tal \& Wansink, 2016).

Despite data visualizations' appearance of objectivity, critics and data visualization experts argue that dataviz do not provide us with neutral windows onto data. Rather, they are the result of numerous choices, it is claimed (Ambrosio, 2015). To engender trust, professional data visualizers may therefore need to be open about the choices they have made in the visualization production process. As news journalists increasingly include data visualizations in their professional toolkit, and because objectivity is an enduring and contested journalistic norm, it is important to examine how journalists perceive the dataviz that they produce in relation to objectivity, and whether and how their perceptions inform transparency practices.

Uncertainty is also central to debate about data visualization. Dasgupta, Chen and Kosara argue that uncertainty is an 'intrinsic part of any visual representation in visualization' (2012, p. 105). They note that multiple aspects of visualization design introduce uncertainty, and the data on which visualizations are based may also contain uncertainties. Thus they distinguish between data uncertainty, which relates to the numeric stratum and is what concerns Anderson, and visual uncertainty, which is specific to data visualization and relates to the visual stratum of dataviz production. We also understand uncertainty in this broad sense, as relating to data, the visual production process, and contexts of consumption, as these also introduce uncertainties. For example, some writers have identified that limited graphicacy (Balchin, 1972), or data visualization literacy, amongst 
audiences (Archer, this volume, and Tønnessen, this volume) produces uncertainty. Goodchild (2009) argues that a further uncertainty relating to consumption results from the ability to share visual information at speed across digital networks, a process in which images are often extracted from their original locations and from related contextualizing information. These consumption-related uncertainties suggest the need for transparency about how data visualizations are produced, and they raise the question of whether and how dataviz practitioners' thinking about audience graphicacy and contexts of consumption informs their transparency practices in dataviz production.

Mechanisms to make uncertainty transparent are widely debated in dataviz literature, such as fuzziness, the location of visual objects, the use of boxplots or related variations (e.g. MacEachren et al., 2012). However, Boukhelifa and Duke argued in 2009 that there was a gap between rhetoric about the importance of visualizing uncertainty and dataviz practice, in which uncertainty is rarely represented outside of laboratory experiments. This raises the question of whether visual techniques are used to make uncertainties transparent in dataviz in the news.

Synthesizing these debates, the overarching question that this chapter addresses is: what is the relationship between dataviz and transparency for news professionals? To answer this primary question, we ask: how do journalists perceive the dataviz that they produce, and to what extent do their perceptions inform transparency practices? To what extent does practitioners' thinking about audience graphicacy and contexts of consumption inform their transparency practices in the dataviz production process? What techniques are used when journalists working with dataviz make uncertainties transparent? We provide some answers to these questions below, after a discussion of our methods.

\section{Methods}

Our chapter draws on interviews with 60 editorial and newsroom leaders, data journalists, visualization designers, and developers in 26 major news organizations in Norway, Sweden, Denmark, Germany, Switzerland, and the United Kingdom. We used a purposive sampling technique, recruiting a balance of newsroom types, from international news providers, national broadcasters, national broadsheet and tabloid newspapers to regional broadcasters and newspapers, all of which had an online presence. Interviewees had many, varied job titles, drawn from journalism, design, IT, 
data science, and elsewhere. Interviews were conducted face-to-face or via video-conferencing, according to a semi-structured interview guide. Each interview lasted about one hour, was audio recorded and then transcribed and anonymized. To aid analysis, the main aspects of the Scandinavian and German-speaking interviews were translated into English. The data were coded and analysed in part deductively according to pre-defined themes and codes, in part inductively as new themes emerged.

Interviewing newsroom practitioners gives access to self-reports and perceptions: our respondents talked about their perceptions of dataviz and they self-reported on their transparency practices. Interview methods do not allow access to actual practices, which would need a different method, and the discussion that follows should be read with this in mind. Below, we discuss how respondents perceive the visual representations of data that they produce in relation to objectivity. Then we focus on mechanisms for 'doing' dataviz transparency in order to build trust amongst audiences, highlighting how reported techniques were surprisingly not visual. Finally, we reflect on transparency strategies for addressing uncertainties relating to audience graphicacy and contexts of consumption.

\section{Perceptions of dataviz and how they inform transparency practices}

To explore how newsroom professionals perceive the data visualizations that they produce and commission in relation to objectivity, and the extent to which their perceptions inform transparency practices, we asked respondents what they saw as the primary function of dataviz in the news, and whether they saw dataviz as offering neutral windows onto data or as shaping the data they represent in certain ways. A small number of respondents said they saw dataviz as a form of truth-telling. Data visualizations add empirical evidence to claims made in news texts, and as such they support the norm of objectivity, these respondents observed:

I think that diagrams may corroborate facts and support credibility. (Data journalist)

However, most respondents felt that data visualizations serve to emphasize the angle of the story in which they are embedded. In this sense, dataviz are shaped by the perspective of the news story. Indeed, one respondent (Developer) described it as lazy not to provide an angle 
onto data, because doing so is the essence of journalistic work. Other respondents concurred:

If you use a data visualization as a central element in a news story, that data visualization also has to carry the angle of the story. (Data journalist)

On the whole, respondents appeared to see data as objective, factual, or truthful, whereas data visualization was more readily seen as a process involving interpretation, and so less objective. In this way, respondents were more likely to acknowledge the uncertainties that can be introduced in visual production and that result from presentational choices than data uncertainties which relate to the numeric stratum that provides the basis for the visualization. One respondent claimed that the visual character of dataviz gives them a false 'quality of objectivity', as Kennedy et al. argue (2016). He said:

The allure of dataviz is it has this visual sense of being objective. There's no adjectives. It looks more neutral than writing a paragraph that says something, which will contain trigger words that make people feel like they're being guided. (Data visualization editor)

This respondent was the only one who questioned the objectivity of the data on which dataviz are based, noting that 'the existence of some data means someone has made a decision to collect it or to compile it, and that decision will usually be made with some ultimate goal in mind'. It was more common for respondents to question the objectivity of the visual representation process, by commenting that producing data visualizations means selection, interpretation, and transformation, as seen in the following quote:

The moment I choose a colour, I have added extra information. Unemployment figures, typhus have no colours. I have to choose one. That is the beginning of interpretation. (Art director)

Many respondents acknowledged that they shape data through the visualization choices that they make. Thus although a small number of respondents indicated that they see dataviz as objective, most did not share this view, instead seeing the process of visualizing data as involving interpretation. This interpretation needs to be made transparent, these respondents noted, 
and they described a number of practices through which they seek to achieve transparency.

Most respondents felt that being transparent about the dataviz production process was important, regardless of whether they saw data visualizations as forms of truth-telling or as involving interpretation. For those respondents who saw dataviz production as a process of selection and interpretation, their views informed their practices, because they believed that these very processes should be made transparent. Many explicitly linked their transparency practices to trust-building:

We have as a principle here to be very transparent. If we have a story that is controversial because we have hit a few choices, so we will tell it, be open about the choices that we have made. (Digital editor)

Respondents described widespread uses of transparency practices which aim to build trust and establish credibility, which we discuss below according to the categories we identified above: data uncertainty, visual uncertainty, and consumption uncertainty.

\section{Data transparency: Linking to sources, sharing datasets}

Crediting sources and linking to sources were seen by respondents as ways of making the process of producing a data visualization transparent. According to respondents, these techniques are taken seriously by the organizations in which they work, although their implementation varies. All respondents said that they credit sources, and some organizations also link to them. Some do this consistently, others do it some of the time. Others have different linking practices for different sources. For example, when using data from its national statistics organization, one newsroom links to the organization's homepage, not to the specific dataset, but this is not how they link to other sources.

There are also differences within newsrooms and across types of stories. One editor said that whether and how they link to data 'depends on what kind of data it is'. A small number of respondents put all the data they have used in a story into a publicly available document, though those who do so believe that these are not widely read. Two respondents noted that their newsrooms have changed their approach to transparency. Previously they provided links to sources, but the 'mobile first' principle of contemporary 
journalism makes this increasingly unfeasible, so now they give thorough accounts of their methods, which we discuss further below.

Some respondents acknowledged that their organizations' transparency practices could be improved, an indication that they felt such practices were important. One reason for limited transparency is that linking to or sharing data is time-consuming. Some respondents reflected on the social role of journalism when talking about crediting, linking to, and sharing datasets. One respondent contemplated how far a news provider should go in the provision of full datasets:

A lot of news media are now offering datasets that the readers can explore more or less freely. I think it's fun, because I work with data. But I don't believe it's journalism, offering no particular angle to the matter. I really don't. (Digital editor)

Another, whose organization no longer links to datasets, explained that he and his colleagues 'build a narrative into the story, rather than giving the data like that, dumping it' (Visual journalist). Another respondent concurred, stating that 'You do not want to publish a 136-page PDF to people and say: here you go. No, we need to break it all down, it is our responsibility to understand what the data say' (Developer). Thus we saw some differences amongst our respondents. A minority saw the sharing of full datasets as a transparency mechanism, but others felt that doing this without telling a story or providing explanation would constitute lazy journalism, because it is the role of journalism to interpret available data.

Many of these practices aim to show that sources are credible and make it possible for audiences to corroborate information. They are intended to show trustworthiness and generate trust. But practices are diverse and not adopted consistently across or within newsrooms. We see this diversity as resulting from the 'interpretative flexibility' of data visualization in the news, a term used within science and technology studies (STS) to characterize sociotechnical assemblages for which a range of meanings exist, definitions are as yet undetermined, and uses are still under negotiation (Wyatt, 1998). Regardless of journalists' views on the objectivity or otherwise of data visualizations, using dataviz in the news involves doing transparency in some way. For those who see data visualizations as objective, transparency practices provide evidence that they are so. For those who see them as the result of interpretation and selection, transparency practices make visible these processes. This is especially the case in relation to the visual stratum of data visualization, as we explain below. 


\section{Visual transparency: Accounting for methods}

Another way of 'doing transparency' when working with dataviz in the news is to account for methods. This was seen by many respondents as a way of making the interpretative work of visualizing data visible. Most respondents stressed that they give thorough accounts of their methods. Some said that being transparent about visual representation process is the right thing to do, suggesting an implicit moral dimension to the practices they described. For others, the moral dimension is more explicit:

First of all it's ethically correct to provide it. Then some people will feel reassured probably, but also it's promoting some sort of culture of using data, reading data. (Data visualization designer)

Ethical standards increase the credibility of a profession, yet in the case of dataviz in the news, such standards are not yet stable, another element of its interpretative flexibility. This, combined with limited audience graphicacy, makes it hard for audiences to evaluate whether ethical standards have been met. Transparency practices provide evidence that ethical standards have been followed, according to this respondent. Thus there is a moral dimension to the emerging dataviz transparency norm. As Schudson noted, journalistic norms are not simply customs, they are also 'moral prescriptions for social behavior' (2001, p. 151).

For a small number of respondents, transparency practices like accounting for methods play a role in the negotiation of objectivity. For these respondents, as for some scholarly commentators, there is a relationship between transparency and objectivity. One respondent suggested that acknowledging the presence of subjective decision-making by making methodology transparent is a way of achieving maximum objectivity, or of convincing 'users that your work is as objective as possible' (Data journalist).

Most respondents said that in their newsrooms, they combine both transparency practices discussed thus far: explaining methods and crediting or linking to sources. A minority goes even further, answering questions about methods on Twitter, even though this is time-consuming, or sharing background work on Pinterest or GitHub. But as with data transparency, some respondents acknowledged that they could 'do transparency' better. The digital editor at a Danish national broadsheet noted that although his organization was good at crediting sources, it was not consistent 'when it comes to accounting for our methods'. Another respondent who worked for 
a national broadcaster noted that while he and his colleagues provided a lot of methodological detail for online visualizations, similar information in relation to broadcast output could be improved.

\section{Techniques not reported: Visual strategies}

Amongst the transparency practices that our respondents described, one thing that was striking was that none of them involved deploying visual strategies for communicating uncertainty, even though the same uncertainties discussed in the dataviz literature concern our respondents. Fuzziness, boxplots, and other visual strategies for communicating uncertainty were not discussed, except by one respondent (Consultant data journalist) who said he was interested in exploring ways of communicating uncertainty in the future.

Instead, respondents reported widespread uses of textual practices through which they aim to be open about their methods and processes and related limitations, as can be seen in the two sections above. Visual design techniques for visualizing uncertainty might exist, but our research suggests that they are not yet established as conventions in the European newsrooms in which we carried out our research. In the absence of established visual conventions through which visualizations can show 'perhaps' or 'probably', language is used - a fact box, a caption, a link to a dataset, to the source of a dataset, or an explanation of methods. These textual strategies were the main mechanisms for 'doing transparency' that our respondents used.

\section{How thinking about audiences and contexts of consumption informs transparency practices}

Respondents' views about audiences, their graphicacy and the contexts within which dataviz circulate also informed their transparency practices, in a small number of cases. Some respondents felt that audiences naively assume that dataviz represent truths about the world - one said, 'At first sight, maps and graphs appear more objective' (Head of data journalism) and another concluded, 'That's why infographics bear such a big responsibility' (Art director). For some, this is problematic. A data journalist said, 'It is problem that people regard numbers and graphics-or to exaggerate, everything that is produced by a machine — as objective truth'. Another 
respondent stated that people are 'too naive about the truthfulness of dataviz'. He continued:

It's like: 'Look here, such is the world!' If there is a map, or a graph, or a chart saying so and so. They will say, 'I have found the evidence of how the world is!' (Data journalist)

In complete contrast, some respondents felt that audiences are too sceptical about the dataviz that they see in the news. Some believed that audience scepticism combined with the proliferation of misinformation to make audiences perceive data visualizations as biased or fake, even when they are not. Two data journalists at the same broadsheet newspaper discussed this problem, expressing concern that despite implementing transparency practices, audiences respond with 'Fake news!', 'This is [your newspaper's] data', or 'This is not true' (Data journalists 1 \& 2).

Kennedy et al. (2016) note that data visualizers understand graphicacy to include the ability to critically assess the trustworthiness of dataviz. Perceived audience naivety (or believing that dataviz represent the truth) and perceived audience scepticism (or the belief that dataviz are biased or fake) can therefore both be understood as limited graphicacy. When data visualizations are shared online, stripped of context and combined with limited audience graphicacy, they introduce uncertainties relating to consumption, as a minority of our respondents noted.

Espeland and Sauder (2007) argue that 'numbers are easy to dislodge from local contexts and reinsert in more remote contexts. Because numbers decontextualise so thoroughly, they invite recontextualisation' (p. 18). In other words, once 'in the wild', data can become separated from the transparency practices discussed in the previous section, which are designed to inform audiences about what the numbers can be taken to represent. This is even more of a problem for visual representations of numbers, as images have even greater 'shareability' than numbers and text (Bruns \& Hanusch, 2017).

One of our respondents talked at length about his organization's attempts to address this problem, noting that 'data visualizations can take a life of their own' because 'it's very easy for a graph that you've done to be robbed of context and taken out' (Editorial developer). This respondent had produced a visualization which explored whether the UK would still have voted to leave the EU if constituency boundaries for this vote were the same as for general elections, and found that it would indeed have done so. This prompted the respondent and his colleagues to reflect on the 
possibility of the visualization being used in political propaganda, asking themselves, 'What can go wrong here, what can go right here? How do we write this up, how do we explain all these things in a way that heads it off?'. To counter the potential decontextualization of the dataviz and their use in misinformation contexts, one strategy he and his colleagues adopted was to embed explanatory text into the graphic file, so that when the image is circulated, explanatory text circulates with it.

Although this concern was not articulated by many respondents, these comments nonetheless indicate that the issue of how to anticipate uncertainties on the consumption, or decoding, side of data visualization are on the agenda in some newsrooms. Encoding transparency into visualization production in ways that acknowledge that consumption contexts are marked simultaneously by audience naivety and scepticism, by debates about truth and post-truth, is an emerging practice. The context of misinformation and the technological assemblages of social media platforms combine to produce a new challenge for journalists, which is heightened by data visualization's visual character, numeric foundations, and contexts of circulation.

\section{Conclusion: Data visualization as enabling transparency and re-establishing trust?}

While Anderson (2018) and McNair (2017) conclude their historical analyses by arguing that there is a need for more transparency and openness about uncertainty in future journalism, in our empirical study of current practice, respondents suggested that these things are well underway. Our empirical research thus fills a gap in the literature, advancing understanding of uses of data visualization and enactments of transparency in contemporary newsrooms.

On the whole, news professionals see working with dataviz as contributing to journalistic transparency in particular ways. Our respondents attempted to be transparent in relation to both data and visual process, regardless of their views about the objectivity or otherwise of the visual and numeric strata of dataviz. The data visualization process demands a series of visual choices which are distinct from the choices made in text-based journalism and which are not yet established as conventions, and so distinct enactments of transparency result from the particular characteristics of data visualization.

Our findings suggest that the networked circulation of news visuals and the context of misinformation both present new possibilities and make new demands with regard to transparency in data visualization, 
and in journalism too. Kennedy et al. (2016) argue that the transparency practices like those that our respondents described not only serve the practical purpose of being transparent; they also serve the rhetorical purpose of performing transparency. They quote Latour, who argues that traceability in the creation of visuals is a key component of their ability to 'transport truth' (Latour, 1995, p. 180). This is another reason for 'doing' transparency.

Our respondents described dataviz transparency practices which are primarily textual accompaniments to visual information, the diversity of which suggests that conventions have not been established. We introduced the concept of interpretative flexibility to explain this indeterminacy. This is something that may change, and the extent to which conventions become established, and whether practices become more visual, should be the subject of future research.

Studies using content analysis (e.g. Engebretsen, 2017; Zamith, 2019) have found transparency work to be less widespread than the picture that our respondents painted. Our respondents' descriptions of their practices suggest that this may be changing, or that there may be a difference between what people say and what they do. Follow-up research using quantitative content analysis could seek to verify what our respondents reported. Our research provides some explanation of why transparency practices are sometimes not undertaken, for example because of limited resources or the view that news professionals should do the work of interpreting data and not leave this to audiences.

Our findings were relatively consistent across the countries in which we carried out our research - the quotes included in this paper come from respondents working in all six of them. Newsroom data visualizers and data journalists belong to a global community which is connected via social media and face-to-face conferences, as a number of our respondents acknowledged. As such, our respondents could be seen as belonging to a global epistemic community which shares similar challenges and experiments with similar solutions. Both the news and dataviz are fields with super-national forms and norms, the development of which crosses borders at digital speed.

\section{Acknowledgements}

The research reported in this chapter was supported by grants from the Norwegian Research Council (NFR) and the Norwegian Media Authorities (RAM). 


\section{References}

Allen, D. (2008). The trouble with transparency: The challenge of doing journalism ethics in a surveillance society. Journalism Studies, 9(3), 323-340. https://doi. org/10.1080/14616700801997224

Ambrosio, C. (2015). Objectivity and representative practices across artistic and scientific visualization. In: A. Carusi, A. S. Hoel, T. Webmoor, \& S. Woolgar (Eds.), Visualization in the age of computerization. (pp. 118-144). London: Routledge.

Anderson, C. W. (2018). Apostles of certainty: Data journalism and the politics of doubt. Oxford: Oxford University Press.

Balchin, W. G. V. (1972). Graphicacy. Geography, 57(3), 185-195.

Boukhelifa, N., \& Duke, D. J. (2009). Uncertainty visualization-Why might it fail? In: CHI Extended Abstracts'og. (pp. 4051-4056). Boston, MA: ACM.

Bruns, A., \& Hanusch, F. (2017). Conflict imagery in a connective environment: Audio-visual content on Twitter following the 2015/2016 terror attacks in Paris and Brussels. Media, Culture and Society, 39(8), 1122-1141. https://doi. org/10.1177/0163443717725574

Coddington, M. (2015). Clarifying journalism's quantitative turn. Digital Journalism, 3(3), 331-348. https://doi.org/10.1080/21670811.2014.976400

Dasgaptu, A., Chen, M., \& Kosara, R. (2012). Conceptualizing visual uncertainty in parallel coordinates. Computer Graphics Forum, 31(3), 1015-1024. https://doi. org/10.1111/j.1467-8659.2012.03094.x

Engebretsen, M. (2017). Levende diagrammer og zoombare kart: Datavisualisering som nyskapende fortellerform i journalistikken. Norsk Medietidsskrift, 24. http:// doi.org/10.18261/issn.0805-9535-2017-02-02

Espeland, W., \& Sauder, M. (2007). Rankings and reactivity: How public measures recreate social worlds. American Journal of Sociology, 113(1), 1-40. http://doi. org/10.1086/517897

Goodchild, M. (2009). Agendas on display [Review of the book PIcturing an uncertain world: How to understand, communicate, and control uncertainty through graphical display, by H. Wainer]. American Scientist, 97(5), 422-424.

Kennedy, H., Hill, R. L., Aiello, G., \& Allen, W. (2016). The work that visualisation conventions do. Information, Communication and Society, 19(6), 715-735. https:// doi.org/10.1080/1369118X.2016.1153126

Karlsson, M. (2010). Rituals of transparency: Evaluating online news outlets' uses of transparency rituals in the United States, United Kingdom and Sweden. Journalism Studies, 11(4), 535-545. https://doi.org/10.1080/14616701003638400

Karlsson, M. Clerwall, C. \& Nord, L. (2017). Do not stand corrected: transparency and users' attitudes to inaccurate news and corrections in online journalism. Journalism \& Mass Communication Quartlery, 94(1): 148-167. 
Kovach, B., \& Rosenstiel, T. (2007). The elements of journalism: What news people should know and the public should expect. New York: Three Rivers Press.

Latour, B. (1986). Visualization and cognition: Drawing things together. Knowledge and Society, 6, 1-40.

MacEachren, A. M., Roth, R. E., O’Brien, J., Li, B., Swingley, D., \& Gahegan, M. (2012). Visual semiotics and uncertainty visualization: An empirical study. IEEE Transactions on Visualization and Computer Graphics, 18(12), 2496-2505.

Masson, E., \& van Es, K. (2017). Visualizing connectivity: Data as evidence in The Architecture of Radio. First Monday, 22(10). http://dx.doi.org/10.5210/fm.v22i110.8039

McNair, B. (2017). After objectivity? Schudson's sociology of journalism in the era of post-factuality. Journalism Studies, 18(10), 1318-1333. https://doi.org/10.1080/ 1461670X.2017.1347893

Porter, T. M. (1996). Trust in numbers: The pursuit of objectivity in science and public life. Princeton: Princeton University Press.

Schudson, M. (2001). The objectivity norm in American Journalism. Journalism 2(2), 149-170. http://doi.org/10.1177/146488490100200201

Singer, J. (2010). Norms and the network: Journalist ethics in a shared media space. In: C. Meyers (Ed.), Journalism Ethics: A philosophical approach. (pp. 227-239). Oxford: Oxford University Press.

Tal, A., \& Wansink, B. (2016). Blinded with science: Trivial graphs and formulas increase ad persuasiveness and belief in product efficacy. Public Understanding of Science, 25(1), 117-125. https://doi.org/10.1177/og63662514549688

Vos, T. P., \& Craft, S. (2017). The discursive construction of journalistic transparency. Journalism Studies, 18(12), 1505-1522. https://doi.org/10.1080/1461670X.2015.1135754

Weinberger, D. (2009). Transparency: The new objectivity. Knowledge Management World. Retreieved January 23, 2019 from http://www.kmworld.com/Articles/ Column/David-Weinberger/Transparency-the-new-objectivity-55785.aspx

Wyatt, S. (1998). Technology's arrow: Developing information networks for public administration in Britain and the United States. Maastricht: Universitaire Pers Maastricht.

\section{About the authors}

Helen Kennedy is Professor of Digital Society at the University of Sheffield. Her research traverses digital landscapes and is currently focused on datafication in everyday life and its visual dimensions.

Martin Engebretsen is Professor of Language and Communication at the University of Agder, Norway. His research areas include text and discourse studies, multimodality, digital journalism and visual communication. 
Wibke Weber is Professor of Media Linguistics at ZHAW Zurich University of Applied Sciences. Her areas of research are data visualization, information graphics, visual storytelling, visual semiotics, multimodality, and augmented and virtual reality. 
